\title{
Personal healthcare budgets: what can England learn from the Netherlands?
}

The English Department of Health proposes to allow people who need continuing care to purchase the services and equipment they think are most appropriate through personal budgets. Yet the Netherlands, which has had a similar system, is in the process of restricting it in the light of problems that have arisen. Ewout van Ginneken, Peter P Groenewegen, and Martin McKee examine what has gone wrong and how England could avoid the same mistakes

\section{Ewout van Ginneken Dutch Commonwealth Fund Harkness fellow in healthcare policy and practice ${ }^{1}$, Peter P Groenewegen director ${ }^{2}$, Martin McKee professor of European public health ${ }^{3}$}

${ }^{1}$ Department of Health Policy and Management, Harvard School of Public Health, Boston, MA, USA; ${ }^{2}$ Netherlands Institute for Health Services Research, Utrecht, Netherlands; ${ }^{2}$ London School of Hygiene and Tropical Medicine, London WC1E 7HT, UK

The English Department of Health wants to give patients more control over the care they receive. One way they propose to do this is through personal healthcare budgets for people eligible for NHS continuing care. The health secretary, Andrew Lansley, says the "budgets will give them more control over how their needs are met, allowing them to choose support and services that suit them and their families." It builds on the English experience with personal budgets for social care, which has suggested potential benefits, especially in empowering budget holders. $^{2}$

English experience with health budgets has so far been limited. ${ }^{1}$ Pilot projects are being undertaken in 64 primary care trusts, of which 20 are included in a Department of Health funded evaluation. A preliminary report from this evaluation, which concedes that the experiences reviewed may be atypical and which was undertaken before most of those interviewed had begun to receive services, identified the things that patients with long term conditions might wish to spend their budgets on, if they had the freedom to do so. ${ }^{3}$ They included not only conventional treatments but also alternative ones, some of which, such as reiki, reflexology, and aromatherapy, are not supported by scientific evidence. They also included services that might increase a sense of wellbeing, such as massage and manicures, and technology, such as laptops and mobile phones.

Although some commentators, including the head of the NHS Confederation, have welcomed personal health budgets, ${ }^{4}$ many questions remain. How will the budgets be set, given that the best risk adjustment models can explain only about $12 \%$ of the individual variation in healthcare costs, so that many people are likely to receive budgets that are either substantially more or less than they need? ${ }^{5}$ What will happen when the budgets are spent? Will the NHS or the patient pick up the bill? Is there a risk that vulnerable individuals might be exploited by unscrupulous providers or brokering agencies, such as those that take extortionate sums to place foreign workers in employment? Will personal budgets accentuate inequalities, especially if they are taken up preferentially by those who are, or have carers who are, most articulate? Is it justifiable at a time of austerity to spend scarce resources on treatments known to be ineffective? None of these, except perhaps the last, can be answered definitively until the budgets are implemented.

A recent research scan by the Health Foundation found that the evidence on the impact of health budgets is extremely weak, with no conclusive proof that they improve health outcomes or save money. ${ }^{6}$ There is, however, some limited evidence that they foster a greater sense of empowerment. The report included 60 studies, most of which were from the United States, the Netherlands, and Germany but only included literature in English, even though the most relevant publications are in Dutch. In this article we examine recent literature and information from the Netherlands, where personal budgets were introduced in 1997, for further insights on how they work.

\section{Continuing care in the Netherlands}

The Dutch system for providing long term care is governed by the 1967 Exceptional Medical Expenses Act (AWBZ), whereby citizens pay $12.15 \%$ of taxable earnings (up to a maximum of about $€ 4000$ a year ( $£ 3390 ; \$ 5370)$ ) into a fund that is used to purchase services, including long term residential care, for people with severe physical and mental disabilities. Eligibility for funding is determined by a Centre for Needs Assessment (CIZ) after a request from patients, their relatives, or their healthcare providers. Entitlement criteria are generally much broader than for long term care in Germany or the United 
Kingdom. ${ }^{7}$ The CIZ is an independent body and assesses the patient and decides what care is required.

Since 1997 patients can choose between receiving care in kind through standard providers or holding a personal budget to purchase care that they choose. As in England, the idea was to give disabled and chronically ill people more control over their care. It was seen as a way of empowering patients, enabling continuing care by family members when the burden of caring increased, and stimulating a market in elements of care that would meet patients' needs more appropriately than what was already available. ${ }^{8}$

Personal budget holders may purchase care from professional organisations or non-professionals, such as neighbours, friends, and family. ${ }^{9}$ The average budget amounted to $€ 43000$ for those assessed for residential care and $€ 12000$ for the others. ${ }^{10}$ If the personal budget is spent, patients have to pay for additional care themselves. However, medical care (covered by the health insurance law) is not part of the budget (box).

As with arrangements for long term care everywhere, the AWBZ scheme rose high on the political agenda because of its increasing costs. However, it was the personal budget element that attracted most attention. The Dutch Ministry of Health has argued that it has become unsustainable. ${ }^{11}$ Between 2002 and 2010 the number of personal budget holders increased 10-fold, from 13000 to 130000 , while spending increased on average by $23 \%$ a year from $€ 0.4 \mathrm{bn}$ to $€ 2.2 \mathrm{bn}$ in the same period, a rate that was much faster than for those without budgets. As of 2010, around $20 \%$ of AWBZ beneficiaries held personal budgets.

The composition and characteristics of the budget holders have changed substantially over the years. The average age of personal budget holders has fallen over time (currently, about $45 \%$ are under 18) and people with somatic diseases, once a majority of budget holders, now comprise only about $20 \% .^{12}$ This is largely explained by increased uptake by children and adolescents with learning disabilities, autistic spectrum diagnoses, and intellectual disabilities who previously received informal, and often unpaid, care.

In the summer of 2010 this led the then minister of health, $\mathrm{Ab}$ Klink, to stop new applications for personal budgets for the rest of that year. Following this move, about 10000 people, comprising about $70 \%$ of total applicants for personal budgets, ${ }^{10}$ chose to be placed on a waiting list for the scheme to recommence rather than receive care in kind. ${ }^{13}$ The nature and motives of those on the waiting list offer valuable insights into the factors driving the growth of personal budgets.

Of those on the waiting list, the largest group (47\%) comprised under 18 year olds with mental health problems and intellectual impairments (represented by their parents), followed by people needing personal care (30\%), who were mostly predominantly over 65 . About half of these people already received professional care and $75 \%$ received (unpaid) informal care (often in combination with professional care). Only 5\% received no help at all. Those who elected to wait for reintroduction of personal budgets saw them as a means of placing them in the driver's seat regarding their care (42\%), as a way of paying their informal caregiver (34\%), and as an opportunity to find care that was not otherwise available (28\%). ${ }^{12}$ (This adds to over $100 \%$ as respondents could select more than one response.)

Increasing cost is not, however, the only problem to have emerged. There have been credible reports of fraud and, although these may not be large in revenue terms, their newsworthiness has provoked public debate. ${ }^{11}$ The assessment of eligibility is not very strict and largely based on trust, while accountability and control mechanisms are lenient. Further concerns have arisen in relation to the growth of specialised agencies that broker arrangements between clients and providers, a practice that lacks effective financial oversight. Research from 2007 showed that even though nine out of 10 personal budget holders are satisfied or very satisfied with their personal budget, $70 \%$ found the rules complicated and a third found administering the budget and its paperwork difficult. Only $35 \%$ administered the budget fully independently, $14 \%$ had help from a family member, and $7 \%$ from a professional. The remainder left the administration entirely to a family member $(36 \%)$ or a professional organisation (8\%). Only a few (10\%) used an agency to purchase care. This helps to explain why specialised agencies see this as an area of potential growth. ${ }^{14}$

\section{The new policy}

From this year the eligibility criteria for personal budgets will change substantially. A series of incremental measures will be implemented that, by January 2014, will substantially restrict access to the scheme. ${ }^{7}$ Only people who would otherwise have to move to a nursing or residential home will be able to keep their budget or apply for one. The money would be used to enable them to continue living at home by purchasing services not available in the formal health and social care system. The Ministry of Health estimates that this will comprise about $10 \%$ of current budget holders. They will also get a 5\% higher allocation in 2012.

To combat fraud in the system, all budget holders will have to open a separate account from which they must make their payments. Furthermore, new budget holders may no longer use specialised agencies to purchase on their behalf. They must also produce a care plan indicating how they will use their funds.

People who are no longer eligible for a personal budget but need care that cannot be provided by regular provider organisations can apply for the funds through the "reimbursement rule for personal care." This makes it possible for them to seek their own care providers within financial limits defined by the AWBZ administration. This additional regulation was introduced to allow people to keep tailor made solutions they had created under the personal budget system.

However, the effect of these changes on people no longer eligible for a personal budget is unclear. Although they remain eligible for AWBZ care, and some may apply for the new reimbursement mechanism, it remains to be seen whether the care is comparable, in terms of its diversity, to what they were able to obtain previously or whether they can retain their previous care arrangements. The government expects that one third of those losing eligibility will decline AWBZ care. ${ }^{10}$

\section{Lessons for England}

The economic context in England is different from that in the Netherlands when the scheme was introduced. The coalition government in the United Kingdom is implementing a programme of unprecedented austerity and it is inconceivable that it will agree to an open ended commitment, as happened in the Netherlands. However, as the Dutch experience shows, it is difficult to reconcile the open ended character of personal budgets and budget ceilings. Even though the English pilots are at an early stage, the preliminary evaluation found that most of those interviewed understood this context. ${ }^{3}$ Some were already paying from their own pockets to obtain services consistent with what they had received previously. Others had already experienced delays in the delivery of equipment or services from third parties and were anxious that this would be a 


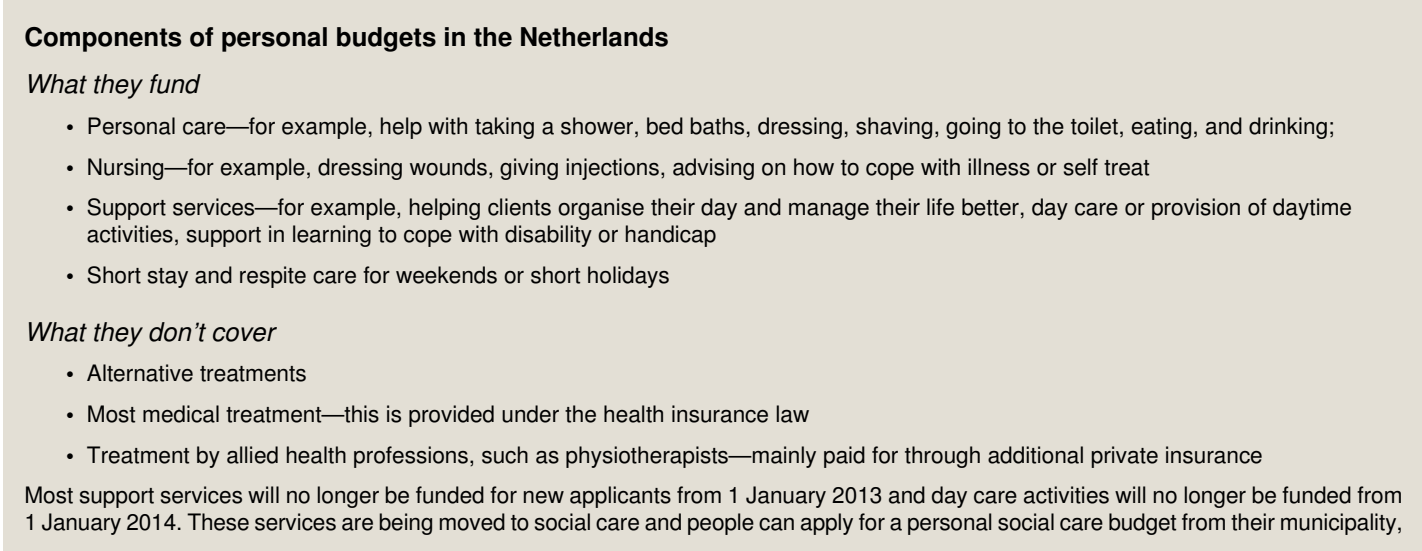

continuing problem. People were also concerned about whether they would be able to find appropriate sources of care and manage their budget - for example, by obtaining adequate receipts and undertaking payroll responsibilities. A particular anxiety was whether the budget would be enough to fund all the treatment or services they needed, especially if these were to increase in the future.

A review by the NHS Confederation has identified other concerns, including start-up costs of on average $£ 93000$ ( $€ 113$ 000; \$143 000) in each location, the systematic disadvantage arising from problems faced by many ethnic minority budget holders when communicating with health professionals; confusion about terminology; lack of enthusiasm among health professionals; and the challenge of releasing necessary funds from existing services in the absence of resources for bridging the transition to the new arrangements. ${ }^{15}$

The Dutch experience shows that some of these anxieties are justified. Administering a budget and finding appropriate care can be challenging and there is evidence that parents of young budget holders are better educated and that budget holders (or their parents) tend to have a higher income and be better able to manage complicated regulations. ${ }^{10}$

If the English proposals are to succeed they will have to establish clear rules and regulations, along with adequate support to enable people to administer their budgets independently, without specialised private agencies. These measures, coupled with strict oversight, would help to prevent waste of public resources and a media backlash over fraud.

The UK government must also recognise that personal budgets can create new demand. The Dutch experience shows that they raise expectations of people who previously were unable to find appropriate care. This may take some time to become apparent. Consequently, eligibility rules and entitlements should be evaluated carefully to avoid creating false expectations and potentially disappointing many people. Even though it is desirable for more people who have specific needs to be enabled to purchase care, additional pressure on the budget may not be what the current government wants to achieve in a time of austerity.

Unless the lessons of the Dutch experience are learnt (box), the unintended and negative consequences will outnumber the positive, empowering role of personal budgets. The details of the government's reforms to the English NHS are still being worked out and it is still far from clear if they will work in practice, ${ }^{16}$ although personal budgets seem certain to become a key element. Many aspects of the reforms represent a leap in the dark but, at least in the case of personal budgets, there are lessons that can be learnt from elsewhere. We can only hope that they are.

Contributors and sources: The article is based on an idea by MM after discussions with EvG and PG. EvG and PG wrote the material on the Netherlands and MM the material on the UK. MM produced the final draft, which was revised by EvG and PG. EvG's views should not be attributed to the Commonwealth Fund or its directors, officers, or staff. Competing interests: All authors have completed the ICMJE uniform disclosure form at www.icmje.org/coi_disclosure.pdf (available on request from the corresponding author) and declare: no support from any organisation for the submitted work; no financial relationships with any organisations that might have an interest in the submitted work in the previous three years, no other relationships or activities that could appear to have influenced the submitted work.

Provenance and peer review: Not commissioned; externally peer reviewed.

1 Lansley A. Speech to Conservative party conference, 4 October 2011. www.politics.co. uk/comment-analysis/2011/10/04/andrew-lansley-speech-in-full

2 Social Care Institute for Excellence. SCIE research briefing 20: the implementation of individual budget schemes in adult social care. SCIE, 2009.

3 Irvine A, Davidson J, Glendinning C, Jones K, Forder J, Caiels J, et al. Personal health budgets: early experiences of budget holders. 2011. www.dh.gov.uk/prod_consum_dh/ groups/dh_digitalassets/documents/digitalasset/dh_130589.pdf.

4 Johnstone R. Personal budgets to be extended to NHS. Public Finance 2011 Oct 5. www. publicfinance.co.uk/news/2011/10/personal-budgets-to-be-extended-to-nhs/.

5 Dixon J, Smith P, Gravelle H, Martin S, Bardsley M, Rice N, et al. A person based formula for allocating commissioning funds to general practices in England: development of a statistical model. BMJ 2011;343:d6608.

6 Health Foundation. Personal health budgets: research scan. Health Foundation, 2010.

7 Sadiraj K, Oudijk D, van Kempen H, Stevens J. De opmars van het pgb. De ontwikkeling van het persoonsgebonden budget in nationaal en internationaal perspectief. Sociaal en Cultureel Planbureau, 2011.

8 Health Foundation. The personal touch. The Dutch experience of personal health budgets. Health Foundation, 2011.

9 Schäfer W, Kroneman M, Boerma W, van den Berg M, Westert G, Devillé W, et al. The Netherlands: health system review. Health Syst Transit 2010;12:1-229.

10 Ministry of Health. Brief aan de Voorzitter van de Tweede Kamer der Staten-Generaal. DLZ-U-3070332. Ministry of Health, 2011.

11 Ministry of Health. Programmabrief langdurige zorg. Brief aan de Voorzitter van de Tweede Kamer der Staten-Generaal. DLZ/KZ-U-3067294. Ministry of Health, 2011.

12 Ramakers C, Van Doorn M, Schellingerhout R. Op weg naar een solide PGB. ITS, Radboud University, 2010.

13 Boer L, Hollander M. Achtergronden en motieven bij wachten op een pgb Eindrapport Een onderzoek in opdracht van het ministerie van VWS Projectnummer: B3811. Research voor Beleid, 2010.

14 Ramakers C, De Graauw K, Sombekke E, Vierke H, Doesborgh J, Wolderingh C. Evaluatie persoongebonden budget nieuwe stijl 2005-2006 [Evaluation of the new version of the personal budget 2005-2006]. ITS, Radboud University, 2007.

15 NHS Confederation. Personal health budgets: countdown to roll-out. NHS Confederation, 2011.

16 McKee M. Does anyone understand the government's plan for the NHS? BMJ 2012;344 e399.

Accepted: 18 January 2012 
Lessons for successful personal health budgets

- Eligibility criteria should be clear and not too broad

- Administrative rules and regulations should be clear and workable for budget holders

- Adequate support should be available so that patients can use and administer their budgets without the need for brokering organisations 